\title{
When and how should surgery be performed in senior colorectal cancer patients?
}

Citation for published version (APA):

Ketelaers, S. H. J., Fahim, M., Rutten, H. J. T., Smits, A. B., \& Orsini, R. G. (2020). When and how should surgery be performed in senior colorectal cancer patients? European Journal of Surgical Oncology, 46(3), 326-332. https://doi.org/10.1016/j.ejso.2020.01.007

Document status and date:

Published: 01/03/2020

DOI:

10.1016/j.ejso.2020.01.007

Document Version:

Publisher's PDF, also known as Version of record

Document license:

Taverne

Please check the document version of this publication:

- A submitted manuscript is the version of the article upon submission and before peer-review. There can be important differences between the submitted version and the official published version of record.

People interested in the research are advised to contact the author for the final version of the publication, or visit the DOI to the publisher's website.

- The final author version and the galley proof are versions of the publication after peer review.

- The final published version features the final layout of the paper including the volume, issue and page numbers.

Link to publication

\footnotetext{
General rights rights.

- You may freely distribute the URL identifying the publication in the public portal. please follow below link for the End User Agreement:

www.umlib.nl/taverne-license

Take down policy

If you believe that this document breaches copyright please contact us at:

repository@maastrichtuniversity.nl

providing details and we will investigate your claim.
}

Copyright and moral rights for the publications made accessible in the public portal are retained by the authors and/or other copyright owners and it is a condition of accessing publications that users recognise and abide by the legal requirements associated with these

- Users may download and print one copy of any publication from the public portal for the purpose of private study or research.

- You may not further distribute the material or use it for any profit-making activity or commercial gain

If the publication is distributed under the terms of Article $25 \mathrm{fa}$ of the Dutch Copyright Act, indicated by the "Taverne" license above, 


\title{
When and how should surgery be performed in senior colorectal cancer patients?
}

\author{
S.H.J. Ketelaers ${ }^{\text {a, }}{ }^{*}$, M. Fahim ${ }^{c}$, H.J.T. Rutten ${ }^{\text {a, b }}$, A.B. Smits ${ }^{c}$, R.G. Orsini ${ }^{\text {a }}$ \\ a Department of Surgery, Catharina Hospital Eindhoven, the Netherlands \\ b GROW: School of Oncology and Developmental Biology, University of Maastricht, Maastricht, the Netherlands \\ ${ }^{\mathrm{c}}$ Department of Surgery, St. Antonius Hospital, Nieuwegein, the Netherlands
}

\section{A R T I C L E I N F O}

\section{Article history:}

Accepted 3 January 2020

Available online 9 January 2020

\section{Keywords:}

Colon cancer

Rectal cancer

Curative surgery

Emergency surgery

Elderly

Survival

\begin{abstract}
A B S T R A C T
Older studies reported high rates of postoperative morbidity and mortality in the senior population, which lead to a tendency to withhold curative surgery in the older population. However, more recent studies showed impressing developments in postoperative outcomes in seniors. Probably, these improvements are due to enhancements in both surgical and non-surgical aspects in the pre-, peri- and postoperative period, such as minimally invasive techniques and anesthesiological insights. The postoperative survival gap seen earlier between younger and older patients is fading. For optimal treatment in the older population, special awareness and care on several aspects is needed. As only a minority of the seniors are frail, a quick frailty assessment is crucial to distinguish the fit from the frail in the decision-making process. In addition, it could be valuable to improve the lacks in physical condition in the preoperative period with the use of prehabilitation programs. Furthermore, it is important to evolve an emergency to an elective setting by postponing emergency surgery to prevent any high-risk situation. In conclusion, based on modern insights, surgery is a valid option in the curative treatment of colorectal cancer in seniors, however individual attention and care is required.
\end{abstract}

๑) 2020 Elsevier Ltd, BASO The Association for Cancer Surgery, and the European Society of Surgical Oncology. All rights reserved.

\section{Introduction}

Colorectal cancer (CRC) is mainly a disease of the older population, with the highest incidence around the age of 80 years old [1]. With increasing life expectancy of the worldwide population, this will result in aging of the population and higher rates of CRC in the oldest population [1]. Therefore, it is not unthinkable that clinicians have to deal more and more commonly with these senior CRC patients.

In older papers, after introduction of TME surgery, seniors did not seem to benefit as much as their younger counterparts [2]. It had been postulated that higher postoperative mortality rates were mainly responsible for this lack of benefit. However, the tide has turned recently. Population-based cohorts from Belgium, Denmark, Sweden and The Netherlands showed that short-term mortality rates are improving over time [3]. Other recent studies show that fit senior patients can be treated the same as younger patients and, when operated on, they have the same outcomes as their younger equivalents [4,5]. Unfortunately, senior patients are less likely to undergo surgery and intensive treatment regimens than their younger counterparts [5-7]. They are believed that they cannot deal with these treatment regimens, due to comorbidities or age $[2,4,6]$. However, these assumptions are based on older studies who reported worse outcomes than nowadays [8,9].

With growing evidence that fit senior patients can deal the stress of curative treatment regimens and increasing numbers of seniors that are affected by CRC, there is a need for clarity about the areas of concern during treatment of these patients [10-12]. Age itself should not lead to withhold curative treatment before the physical status of the senior patients is assessed [4-6]. As senior patients are not included in most clinical trials, evidence is based on younger patients $[5,6]$. Fortunately, there are expert recommendations on how to treat this senior population, as standard guidelines focus particularly on middle aged patients [6,13].

In this paper a surgery-focused recommendation is outlined why, when and how we should treat the senior CRC patient.

\footnotetext{
* Corresponding author. Department of Surgery, Catharina Hospital, PO Box 1350, 5602 ZA, Eindhoven, the Netherlands.

E-mail address: stijn.ketelaers@catharinaziekenhuis.nl (S.H.J. Ketelaers).
} 


\section{Which changes have been made over the years to improve outcomes after colorectal cancer surgery?}

\section{Minimally invasive surgery}

Laparoscopic colorectal cancer surgery is safe and has comparable oncological results as open surgery $[6,14]$. There is no difference between laparoscopic and open surgery in harvested lymph nodes, circumferential resection margins, recurrence rates, and overall and disease-free survival [14,15]. In addition, minimal invasive surgical techniques evoke less intensive immune response than open surgery, thus reducing the surgical stressor [16]. This could be an explanation for the improved recovery seen after laparoscopic surgery with less postoperative pain, shorter hospital admissions and less postoperative and cardiopulmonary complications $[5,15,17,18]$. Also in the older population, laparoscopic CRC surgery is safe and goes with less postoperative morbidity [18-20].

In select cases, organ-sparing techniques like polypectomy, transanal excisions (TAE) and transanal endoscopic microsurgery (TEM) can be the solution [6]. Organ-sparing techniques have less morbidity and excellent functional results, with acceptable oncological results [6]. For rectal cancer, good oncological outcomes with local excisional techniques are achieved in T1 tumors with minimal submucosal and no lymphovascular invasion, when no poor differentiation, mucinous histology and budding is present [6]. For malignant colorectal polyps in general, similar oncological results after radical polypectomy were seen as after surgical resections [21]. It is important to weigh balances between both oncological and surgical outcomes before choosing for these local techniques. As some senior patients are frail or could prefer good functional outcomes over survival benefit, it is important to discuss this with the patient using shared decision making.

\section{Organ preservation in rectal surgery}

In about $20 \%$ of the patients treated with neoadjuvant treatment, complete pathological response is observed [22]. When complete response is achieved after neoadjuvant rectal cancer treatment, there is a possibility for a watch-and-wait approach [23]. Complete responders of neoadjuvant chemoradiotherapy are assessed and followed with MRI and endoscopy [22]. With this more conservative approach with intensive surveillance, acceptable rates of local recurrence and high rates of survival are found in clinical responders $[22,24,25]$. About $10-30 \%$ need delayed salvage surgery to resect regrowth and only a small percentage of them had unresectable recurrences, so in highly selected patients it could be an effective method to avoid surgery [23,25].

The standard for treating rectal cancer remains surgery with or without neoadjuvant treatment [22]. Although watch-and-wait procedures have similar cancer-specific and overall survival rates, surgery is associated with higher rates of disease-free survival and a smaller risk of technically unresectable recurrences [25]. However, in patients who are at risk to undergo surgery or when functional outcomes and the avoidance of a permanent stoma are important, it could be better to have a more conservative approach that only consists of neoadjuvant treatment followed by the watch-and-wait protocol [22,25]. In short, in selected patients with clinical complete response, the watch-and-wait protocol could be an adequate surrogate to surgery [22].

\section{Effect of colorectal differentiation on outcome}

One of the effects seen of subspecialization in surgery is improved surgery-related outcomes [26]. Higher CRC volumes and colorectal subspecialization improves outcomes and survival
[27-29]. Specialized and high-volume surgery is also related to less anastomotic leakages, lower postoperative mortality and recurrence rates [28,30,31]. Especially in more complex surgery, like advanced rectal cancer surgery, high-volume and specialized surgery is associated with more sphincter-preserved surgery, lower rates of permanent stoma formation, better local control and increased survival [26,32]. Only those senior patients with advanced cases, or seniors in whom an increased risk of morbidity or mortality is expected, a referral can be considered.

\section{Need for changing the perspective of surgical treatment of the senior} patient with colorectal cancer

The current belief that seniors could not manage curative treatment regimens is based on older studies that show associations between senior patients and high rates of postoperative morbidity and mortality $[2,33]$. These outcomes lead to a decrease in older patients receiving curative surgery, enlarging the risk of undertreatment [6,34]. Fortunately, there is increasing evidence showing seniors who are fit for surgery, have the same benefit from curative treatment as younger patients do [9,11,35]. With improving the surgical circumstances over the years, declining rates of postoperative morbidity and mortality have been described for this population $[8,9,36]$. In earlier studies high rates of one-year mortality in senior patients of about $19-26 \%$ were reported and were much higher than in younger patients [37-39]. A populationbased study from The Netherlands showed an improvement in short-term mortality after CRC surgery in the senior population between 2009 and 2013 [36]. For colon and rectal cancer patients $\geq 75$ years 1 -year mortality decreased from $18.5 \%$ to $15.0 \%$ and from $15.3 \%$ to $11.7 \%$, respectively. Nevertheless, these rates were still much higher than in younger patients [36]. Another populationbased study across four North-European countries and also other population-based studies showed improvement in short-term mortality rates over time $[3,40,41]$.

Possible explanations for this major improvement in short-term mortality rates for seniors are better staging, increased use of minimally invasive techniques, perioperative care, awareness of complications, expertise and high-volume care [9,36]. Other possible contributing factors are insights in perioperative anesthesiological factors, which include administration of antibiotics, preservation of body temperature and adequate fluid balances $[42,43]$.

More recently, a study using Dutch population-based data analyzed the developments of postoperative mortality and 1-year

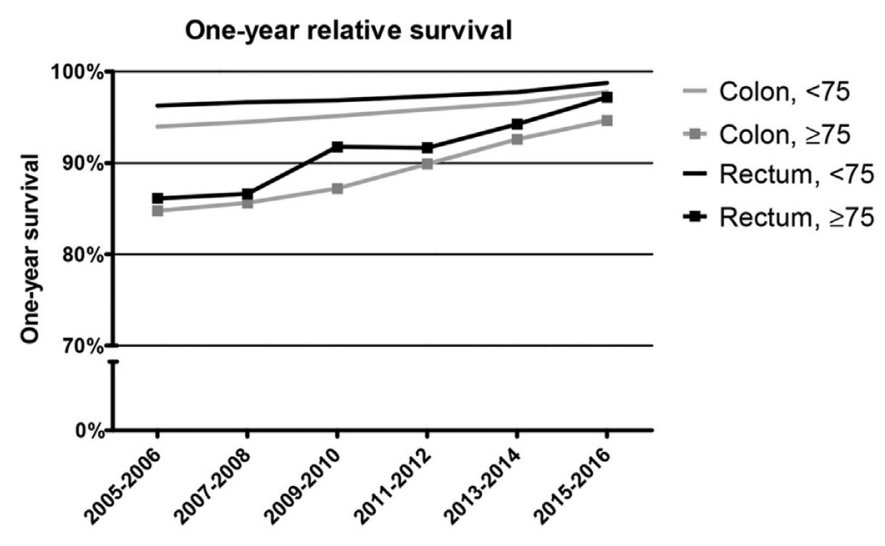

Fig. 1. Relative one-year survival rates for both colon and rectal cancer patients after receiving surgery between 2005 and 2016 in the Netherlands, as published by Brouwer et al. [8]. 
relative survival in CRC patients between 2005 and 2016 [8]. Improvements in 30-day mortality for senior patients to $4.0 \%$ and $2.7 \%$ were seen, for colon and rectal cancer, respectively [8]. The relative 1 -year survival rates improved to $94.6 \%$ and $97.2 \%$, for colon and rectal cancer respectively [8]. (Fig. 1) These rates were almost comparable to those in younger patients [8]. In addition, a recently published study from a high-volume center for complex cases showed 30-day mortality rates for senior CRC patients of $1.2 \%$ ( $1.1 \%$ for senior colon and $1.4 \%$ for senior rectal cancer patients) and 1year relative survival rates of 94.3\% [9]. These rates were also comparable to younger patients [9]. (Table 1).

While one-year mortality after CRC surgery has been a major concern in the past for seniors, recent studies show a major increase in survival, both for specialized and general CRC surgical centers $[2,8,9]$. The earlier reported mortality rates in seniors should no longer be used to form a basis to withhold CRC treatment in older patients $[8,9]$. However, we are aware that special care and attention is needed in this population and that individual differences in frailty levels need to be assessed preoperatively.

\section{When and how to treat?}

\section{Staging}

Treatment for all colorectal cancer patients starts with adequate staging of the primary tumor and an estimation of the patient' performance status. Primary diagnosis is done by colonoscopy and biopsy for histological examination on the characteristics of the tumor [44]. A Computed Tomography (CT) is advised for tumor staging and to examine the possibility of lymph node involvement and/or (extra)hepatic metastasis [44]. In rectal cancer, the Magnetic Resonance Imaging (MRI) provides detailed views of dissection planes, pelvic organs and mesorectal fascia and circumferential margins (CRM) [45].

\section{Frailty assessment}

In senior patients an estimation of their performance status is important to reveal frailty. Frailty is defined as a state of diminished physiological reserve capacity across multiple organ systems [46]. As a result of frailty the capacity to withstand stressors, such as intensive treatment, is reduced, which is associated with postoperative complications, hospitalization, and reduced survival after surgery [6,47-49].

It has to be clear that only a small percentage of the senior population is considered frail. Therefore, in the older population it is important to distinguish the frail from the fit senior. But it is not clear how to identify frailty in the individual patient, as no one tool is accurate enough to include all differences between older patients $[6,50]$. Extensive and comprehensive assessment of frailty on a routinely basis is time-consuming and resource intensive, as many geriatricians are needed to be involved to evaluate every older patient who undergoes CRC surgery [12,45]. For most hospitals it is difficult to implement this as standard care. Therefore, other less time-consuming tools are needed in daily practice to screen for frailty and to distinguish those patients that benefit from an assessment by a geriatrician prior to treatment [6]. In the most recent published expert opinion on how to treat senior rectal cancer patients, the focus should lie on identifying the main predictors of frailty and postoperative complications such as functional status, nutritional status, and comorbidities [6].

Functional status is easily assessed during the patient's visit with the timed-up-and-go test (TUG), since a high TUG is able to predict the risk of postoperative complications [51]. Also a history of falls in the last 6 months before surgery is associated with a higher risk of postoperative complications [12]. Other possible tools given by the expert group are the G8 score to determine health and nutritional status and medication use and the Mini-Cog score for the evaluation of cognitive status [6]. Since 2012, as part of a National Patient Safety Program, all patients over 70 years in the Netherlands should be screened for frailty by assessing the following domains: undernutrition, physical impairment, delirium risk and fall risk [52]. Other important factors to evaluate could be the mental status, alcohol and smoking habits, supporting system and the willing to fight for recovery of the patient. As it could be possible that some seniors tend to give up earlier when feeling bad, discussing that some symptoms like fatigue, nausea or weakness are normal during recovery after colorectal surgery, could be of significance.

If no frailty is expected the patient should be offered an optimal treatment. When after the previous mentioned quick and easily applicable screening methods, the patient is at risk, the selected patient should be referred to a geriatrician to perform a full comprehensive geriatric assessment. This full assessment evaluates the multiple domains of frailty, such as physical, nutritional, functional and psychosocial health status, cognition and polypharmacy [50]. When after this geriatric assessment the patient seems fit standard curative care can be performed. However, in case the patient is considered frail, prehabilitation programs should be started to increase the patient's condition before surgery is performed or the treatment regimen should be fine-tuned to the health status of the individual patient. In addition, when the patient is considered frail, it could be of importance to discuss the patient in a regional multidisciplinary team meeting (MDT) with incorporated geriatricians for the whole decision-making process.

\section{Prehabilitation}

Older patients who undergo CRC surgery are at risk for delayed recovery, and prehabilitation could enhance the capacity to tolerate surgery and to recover earlier [53]. It seems to be a promising method to increase the physical condition of the senior patients

Table 1

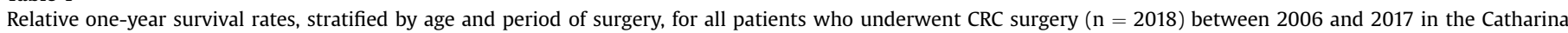
Hospital, Eindhoven [9].

\begin{tabular}{|c|c|c|c|c|c|c|}
\hline & \multicolumn{6}{|c|}{ Relative one-year survival } \\
\hline & \multicolumn{2}{|l|}{$2006-2012$} & \multirow[t]{2}{*}{ p-value } & \multicolumn{2}{|l|}{$2013-2017$} & \multirow[t]{2}{*}{ p-value } \\
\hline & $<75$ years & $\geq 75$ years & & $<75$ years & $\geq 75$ years & \\
\hline & $\%$ & $\%$ & & $\%$ & $\%$ & \\
\hline All CRC patients $(\mathrm{n}=2018)$ & $96.5 \%$ & $88.4 \%$ & $<0.001$ & $95.5 \%$ & $94.3 \%$ & 0.429 \\
\hline Colon $(n=1037)$ & $96.5 \%$ & $87.3 \%$ & $<0.001$ & $95.3 \%$ & $94.7 \%$ & 0.429 \\
\hline Rectum $(\mathrm{n}=981)$ & $96.3 \%$ & $89.4 \%$ & 0.003 & $95.3 \%$ & $91.2 \%$ & 0.176 \\
\hline Emergency surgery $(n=158)$ & $100 \%$ & $69.8 \%$ & $<0.001$ & $87.2 \%$ & $92.1 \%$ & 0.479 \\
\hline
\end{tabular}


prior to surgery, and reductions of about $50 \%$ in postoperative complications are seen in intra-abdominal surgery [54]. Although, clear evidence on postoperative outcomes in colorectal cancer surgery is still lacking [49].

Especially in selected patients, improvement of preoperative physical status could be beneficial in improving postoperative outcomes [55]. Seniors with lack of physical condition and muscle strength have an increased risk for postoperative complications, and therefore these are targets for prehabilitation programs $[12,49]$. In particular senior patients with the lowest baseline fitness benefit most from these programs [56]. Until now, it is still not exactly known which aspects the best prehabilitation programs should include and what the optimal timing and duration of these programs should be [6]. Probably, these programs should contain multimodal interventions such as physical training, smoking cessation, nutritional support and psychological support [53,56,57].

The prehabilitation program should start with assessing where the patient is lacking in condition and what the situation and possibilities of the patient are. As home-based training has shown some good results in prehabilitation programs, training at home could be considered if preferred by the patient [58]. While in other cases, it could be preferred to train with a physiotherapist. Ideally, these programs should take place in the waiting period between diagnosis and surgery. This period can be used optimally by letting patients participate in prehabilitation programs to improve their condition. In case of advanced rectal cancer where neoadjuvant treatment is needed, this period is often longer and can extend up to 12 weeks, which makes it feasible to perform a longer and possibly more effective prehabilitation program to improve the patient's condition. Although prehabilitation needs time to take its effect, until now it is not clear whether long prehabilitation programs are more effective than short programs [59]. However, it is believed that these programs should be given to patients where there is at least about 2 weeks, and ideally $4-6$ weeks, prior to surgery [59]. Participating in prehabilitation programs can help to lower the impact of neoadjuvant regimens on physical condition [60]. In patients that are considered frail, response to prehabilitation can also help to determine if they can receive curative treatment with surgery or it is better to perform best supportive/ palliative treatment.

\section{Nutritional status}

About one in five CRC patients is malnourished before surgery [61]. Poor nutritional state is associated with adverse postoperative outcomes, while good nutritional status is important for muscle gain and recovery $[49,53,62]$. So, improving nutritional status preoperatively seems important to create an anabolic instead of a catabolic state. Supplementation of proteins in addition to physical training could be beneficial to increase muscle gain [57]. Additionally, some proteins have shown some anti-inflammatory and immune-modulating effects [53]. Supplementation of vitamin D and multivitamins, which are often deficient in seniors, could be beneficial as vitamin $\mathrm{D}$ is associated with muscle mass and strength [57,63]. Although the use of nutritional interventions has not yet been proven, it seems that when nutritional interventions are integrated with other prehabilitation modalities, clinically meaningful enhancements could be made in outcomes [62,64].

\section{Comorbidity}

Older patients with CRC often have other chronic diseases to deal with, about $60 \%$ of CRC patients over 70 years suffer from any comorbidity [65]. Each comorbidity has a different impact on physical function and postoperative outcomes, but patients with comorbidities in general do not especially develop more surgical complications than those without comorbidities [65,66]. As having comorbidities is not the same as frailty and frailty is influenced only by a few specific comorbidities, it is important to know the impact of each comorbidity on postoperative outcomes [65,67]. Most seniors with CRC have comorbidities like cardiovascular and pulmonary diseases, which both increase the operative and postoperative risk of morbidity and mortality [67,68]. Patients with colorectal cancer and a preoperative diagnosis of deep venous thrombosis (DVT) also have an increased risk of developing postoperative complications [65]. Therefore, when patients suffer preoperatively from a DVT, it is important to give extra attention to regulate their hemostasis both pre- and postoperatively to prevent complications and to increase survival $[65,68]$. Also neurological comorbidities in the presence of CRC increases the risk of negative postoperative outcomes [68]. Other prevalent comorbidities seen in CRC patients are hypertension, diabetes and previous malignancies, but these have minimal impact on frailty and postoperative outcomes [65,69]. However, some comorbidities do play a role in survival and must be taken into account during the decision-making process. Preoperative treatment and regulation of the patients' comorbidities is important and may reduce the peri- and postoperative morbidity and mortality [70].

\section{Emergency surgery}

About $15 \%$ of colon cancer patients present with acute obstruction [71]. Emergency surgery is considered as a major risk factor for postoperative mortality in comparison to elective surgery, especially in the senior CRC patient [71]. In addition, they died earlier after surgery and had higher rates of complications compared to younger patients [71]. However, it has been shown that relative survival rates do not differ between older and younger obstructed colon and rectal cancer patients, which implicates that curative treatment of these seniors is beneficial [9,71]. Even in emergency cases, age itself should not be the most important factor in decision-making $[9,71]$.

In obstructed colon cancer, surgery is also the primary treatment modality [71]. However, it is still not known which surgical technique is the best and whether stent as bridge to surgery should be performed or not [71]. The rationale behind stenting as bridge to surgery is to initially decompress the distended colon to transform an emergency resection into an elective procedure with optimized circumstances [72]. Although guidelines even recommend the use of stent placement as bridge to surgery for seniors who are at risk, it is not frequently performed because of safety concerns [72]. Recently it is shown that the use of a stent as bridge to surgery is safe and provides an alternative to emergency resections, especially in high-volume centers [72]. In addition, it is associated with higher rates of laparoscopy and lower rates of postoperative morbidity and permanent stomas than after emergency resection [72,73]. Although not statistically significant, a meta-analyses showed a tendency to higher tumor recurrence rates in the stent group than after emergency surgery. However, short-term mortality and overall and disease-free survival rates were not impaired in the stent-group [72,73].

Another alternative to emergency surgery is the obstruction protocol, which has been developed by some of the authors (M.F., A.S.) [74]. (Fig. 2) This protocol aims to postpone surgery for several weeks allowing proper prehabilitation. Especially in the older patient who is in an emergency situation and thus depleting their physical reserves, prehabilitation is important to reduce postoperative morbidity. The obstruction protocol consists of reduction of prestenotic dilatation and abdominal pain, thus preventing emergency surgery and providing time for prehabilitation, both in regards to physical and nutritional status. The prestenotic distention 
- Stenotic abnormality in colon, rectum or ileocaecum

- Abdominal pain or borborygmi

- CT/MRI: bowel segment or whole (large) bowel distended

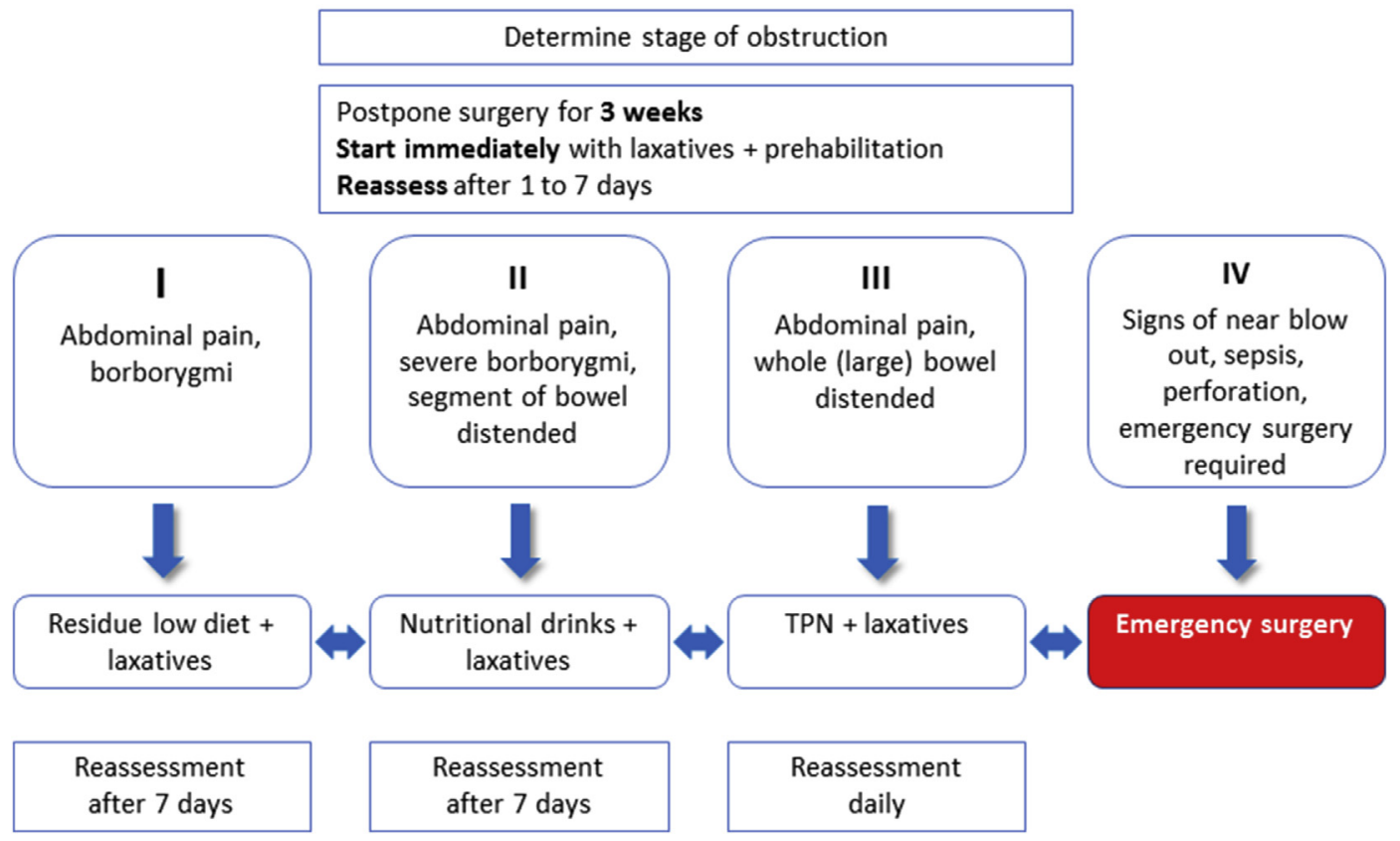

Fig. 2. Flowchart for postponing emergency surgery in case of obstruction, as described by Fahim and Smits et al. [74].

of the bowel wall and the stenosis of these patients causes pain and malabsorption leading to chronic insufficient intake and lethargy which in turn causes suboptimal physical and nutritional condition [75]. In this obstruction protocol, patients that present with obstructed colon cancer receive dietary adjustments and oral laxatives to reduce the amount of stool produced. The reduced volume of stool can more easily pass the obstructive bowel. This will reduce prestenotic bowel wall distension and consequently abdominal pain. In the absence of bowel wall distension and abdominal pain the need for emergency surgery disappears. Surgery can be postponed, planned electively after preferably 3 weeks and conducted by a specialized colorectal surgeon, laparoscopically or robot-assisted. It also provides time for proper prehabilitation of the patient such as improving physical status, smoking cessation and reduction of alcohol consumption prior to elective surgery. The dietary measures that were given to reduce the amount of stool also covered all the nutritional needs of the patient and subsequently ensured adequate caloric intake which resulted in the patient leaving the catabolic state. According to the severity of obstruction the patients are given diets ranging from residue-low diet to total parenteral nutrition. In the senior patient these measures that can enhance nutritional and physical condition can make an important difference. Promising results have been shown in a pilot study and are now further investigated in a multicenter setting [74].

In obstructed rectal cancer with an impending cecum blow-out, it seem necessary to perform a deviating stoma first and to perform resectional surgery in an elective setting after adequate staging and neo-adjuvant treatment when needed [45]. During this period it could also be possible to use the obstruction protocol to improve the circumstances and the patients' condition as a bridge to definitive surgery.

\section{Conclusion}

The poor outcomes in the past of colorectal surgery do not reflect daily practice anymore. Colorectal surgery can be performed safely without increased postoperative morbidity and mortality and without excess one-year mortality. Several changes in the management have contributed to this lapse in outcome i.e.: better preoperative assessment and prehabilitation, less traumatic surgery and non-surgical organ preservation treatments, perioperative care focussing on nutritional, electrolyte and fluid balance, new anesthesiological techniques, early postoperative mobilization etc. The most important contribution solving this problem was the understanding that a multidisciplinary approach is necessary, and the recognition that actions may be needed to be taken before any invasive treatment.

Within this multidisciplinary setting, even more frail patients may undergo treatment. The development of special MDTs for seniors, who have to undergo major surgery, with a dedicated team encompassing not only a surgeon and anesthesiologist, but also a geriatrician has to be applauded.

Programs to deal with specific problems like acute obstruction, which still carries the highest risks for senior people, have to be developed further and implemented on a major scale.

If surgery is necessary for cure, surgery is a valid option for most senior citizens with colorectal cancer. Counselling and shared decision making should be based on modern insights in surgical outcomes rather than on outdated data.

\section{Funding}

None. 


\section{Declaration of competing interest}

\section{None.}

\section{References}

[1] Winther SB, Baatrup G, Pfeiffer P, Qvortrup C. Trends in colorectal cancer in the elderly in Denmark, 1980-2012. Acta Oncol 2014;55:29-39.

[2] Rutten HJT, den Dulk M, Lemmens VEPP, van de Velde CJH, Marijnen CAM Controversies of total mesorectal excision for rectal cancer in elderly patients. Lancet Oncol 2008;9:494-501.

[3] Claassen YHM, Bastiaannet E, van Eycken E, van Damme N, Martling A, Johansson R, et al. Time trends of short-term mortality for octogenarians undergoing a colorectal resection in North Europe. Eur J Surg Oncol 2019;45: 1396-402.

[4] Mazzari A, Taomaiuolo P, Perrone F, Sicoli F, Crucitti A. Surgical management of colorectal cancer in the elderly patient. In: Crucitti A, editor. Surgical management of elderly patients. City: Springer; 2018. editor^, editors.

[5] Millan M, Merino S, Caro A, Feliu F, Escuder J, Francesch T. Treatment of colorectal cancer in the elderly. World J Gastrointest Oncol 2015;7:204-20.

[6] Montroni I, Ugolini G, Saur NM, Spinelli A, Rostoft S, Millan M, et al. Personalized management of elderly patients with rectal cancer: expert recommendations of the European society of surgical oncology, European society of coloproctology, international society of geriatric oncology, and American college of surgeons commission on cancer. Eur J Surg Oncol 2018;44: 1685-702.

[7] Hathout L, Maloney-Patel N, Malhotra U, Wang S, Chokavatia S, Dalal I, et al. Management of locally advanced rectal cancer in the elderly: a critical review and algorithm. J Gastrointest Oncol 2018;9:363-76.

[8] Brouwer NPM, Heil TC, Olde Rikkert MGM, Lemmens VEPP, Rutten HJT, de Wilt JHW, et al. The gap in postoperative outcome between older and younger patients with stage I-III colorectal cancer has been bridged; results from The Netherlands cancer registry. Eur J Canc 2019;116:1-9.

[9] Ketelaers SHJ, Orsini RG, Burger JWA, Nieuwenhuijzen GAP, Rutten HJT. Significant improvement in postoperative and 1-year mortality after colorectal cancer surgery in recent years. Eur J Surg Oncol 2019;45:2052-8.

[10] Itatani Y, Kawada K, Sakai Y. Treatment of elderly patients with colorectal cancer. BioMed Res Int 2018;2018:2176056.

[11] Jung B, Pahlman L, Johansson R, Nilsson E. Rectal cancer treatment and outcome in the elderly: an audit based on the Swedish rectal cancer registry 1995-2004. BMC Canc 2009;9.

[12] Samuelsson KS, Egenvall M, Klarin I, Lökk J, Gunnarsson U. Preoperative geriatric assessment and follow-up of patients older than 75 years undergoing elective surgery for suspected colorectal cancer. J Geriatr Oncol 2019;10: 709-15.

[13] Matsuoka H, Maeda K, Hanai T, Sato H, Masumori K, Koide Y, et al. Surgical management of colorectal cancer for the aging population-a survey by the Japanese Society for Cancer of Colon and Rectum. Asian J Surg 2018;41:192-6.

[14] Fujii S, Tsukamoto M, Fukushima Y, Shimada R, Okamoto K, Tsuchiya T, et al. Systematic review of laparoscopic vs open surgery for colorectal cancer in elderly patients. World J Gastroenterol 2016;8:573-82.

[15] Chen K, Cao G, Chen B, Wang M, Xu X, Wenwen C, et al. Laparoscopic versus open surgery for rectal cancer: a meta-analysis of classic randomized controlled trials and high-quality Nonrandomized Studies in the last 5 years. Int J Surg 2017;39:1-10.

[16] Veenhof AAFA, Vlug MS, van der Pas MHGM, Sietses C, van der Peet DL, de Lange-de Klerk ESM, et al. Surgical stress response and postoperative immune function after laparoscopy or open surgery with fast track or standard perioperative care. Ann Surg 2012;255:216-21.

[17] van Bree S, Vlug M, Bemelman W, Hollman M, Ubbink D, Zwinderman K, et al. Faster recovery of gastrointestinal transit after laparoscopy and fast-track care in patients undergoing colonic surgery. Gastroenterology 2011:141:872-80.

[18] Antoniou SA, Antoniou GA, Koch OO, Pointer R, Granderath F. Laparoscopic colorectal surgery confers lower mortality in the elderly: a systematic review and meta-analysis of 66,483 patients. Surg Endosc 2015;29:322-33.

[19] Devoto L, Celentano V, Cohen R, Khan J, Chand M. Colorectal cancer surgery in the very elderly patient: a systematic review of laparoscopic versus open colorectal resection. Int J Colorectal Dis 2017;32:1237-42.

[20] Lim SW, Kim YJ, Kim HR. Laparoscopic surgery for colorectal cancer in patients over 80 years of age: the morbidity outcomes. Ann Surg Treat Res 2017;92: 423-8.

[21] Lopez A, Bouvier A, Jooste V, Cottet V, Romain G, Faivre J, et al. Outcomes following polypectomy for malignant colorectal polyps are similar to those following surgery in the general population. Gut 2019;68:111-7.

[22] van der Valk MJM, Hilling DE, Bastiaannet E, Meershoek-Klein Kranenbarg E, Beets GL, Figueiredo NL, et al. Long-term outcomes of clinical complete responders after neoadjuvant treatment for rectal cancer in the International Watch \& Wait Database (IWWD): an international multicentre registry study. The Lancet 2018;391:2537-45.

[23] Beets GL, Figueiredo NL, Habr-Gama A, van de Velde CJH. A new paradigm for rectal cancer: organ preservation: introducing the international watch \& wait database (IWWD). Eur J Surg Oncol 2015;41:1562-4.

[24] Maas M, Beets-Tan RGH, Lambregts DMJ, Lammering G, Nelemans PJ,
Engelen SME, et al. Wait-and-See policy for clinical complete responders after chemoradiation for rectal cancer. J Clin Oncol 2011;29:4633-40.

[25] Dossa F, Chesney T, Acuna SA, Baxter NN. A watch-and-wait approach for locally advanced rectal cancer after a clinical complete response following neoadjuvant chemoradiation: a systematic review and meta-analysis. Lancet Gastroenterol Hepatol 2017:2:501-13.

[26] Anwar S, Fraser S, Hill J. Surgical specialization and training - its relation to clinical outcome for colorectal cancer surgery. J Eval Clin Pract 2012;18:5-11.

[27] Hall GM, Shanmugan S, Bleier JIS, Jeganathan AN, Epstein AJ, Paulson EC. Colorectal specialization and survival in colorectal cancer. Colorectal Dis 2015;18:51-60.

[28] Paulson EC, Mitra N, Sonnad S, Armstrong K, Wirtalla C, Kelz RR, et al. National Cancer Institute designation predicts improved outcomes in colorectal cancer surgery. Ann Surg 2008;248:675-86.

[29] Barbas AS, Turley RS, Mantyh CR, Migaly J. Effect of surgeon specialization on long-term survival following colon cancer resection at an NCI-designated cancer center. J Surg Oncol 2011;106:219-23.

[30] Dorrance HR, Docherty GM, O'Dwyer PJ. Effect of surgeon specialty interest on patient outcome after potentially curative colorectal cancer surgery. Dis Colon Rectum 2000;43:492-8.

[31] Smith JA, King PM, Lane RH, Thompson MR. Evidence of the effect of 'specialization' on the management, surgical outcome and survival from colorectal cancer in Wessex. Br J Surg 2003;90:583-92.

[32] Archampon W, Borowski D, Wille-Jørgensen P, Iversen LH. Workload and surgeon's specialty for outcome after colorectal cancer surgery. Cochrane Database Syst Rev 2012;14.

[33] Shahir MA, Lemmens V, van de Poll-Franse LV, Voogd AC, Martijn H, JanssenHeijnen MLG. Elderly patients with rectal cancer have a higher risk of treatment-related complications and a poorer prognosis than younger patients: a population-based study. Eur J Canc 2006;42:3015-21.

[34] Claassen YHM, Vermeer NCA, Iversen LH, van Eycken E, Guren MG, Mroczkowski P, et al. Treatment and survival of rectal cancer patients over the age of 80 years: a EURECCA international comparison. Br J Canc 2018;119: 517-22.

[35] Dekker JWT, van den Broek CBM, Bastiaannet E, van de Geest LGM, Tollenaar RAEM, Liefers GJ. Importance of the first postoperative year in the prognosis of elderly colorectal cancer patients. Ann Surg Oncol 2011;18: 1533-9.

[36] Breugom AJ, Bastiaannet E, Dekker JWT, Wouters MWJM, van de Velde CJH, Liefers GJ. Decrease in 30-day and one-year mortality over time in patients aged $>75$ years with stage I-III colon cancer: a population-based study. Eur J Surg Oncol 2018;44:1889-93.

[37] Dinnewitzer A, Nawara C, Augschîll C, Neureiter D, Hitzl W, offner D, et al. The impact of advanced age on short- and long-term results after surgery for colorectal cancer. Eur Surg 2015;47:331-6.

[38] Kornmann VNN, van Vugt JLA, Smits AB, van Ramshorst B, Boerma D. The first year after colorectal surgery in the elderly. Ann Coloproctol 2017:33:134-8.

[39] Weerink LBM, Gant CM, van Leeuwen BL, de Bock GH, Kouwenhoven EA, Faneyte IF. Long-term survival in octogenarians after surgical treatment for colorectal cancer: prevention of postoperative complications is key. Ann Surg Oncol 2018:25:3874-82.

[40] Jafari MD, Jafari F, Halabi WJ, Nguyen VQ, Pigazzi A, Carmichael JC, et al, Colorectal cancer resections in the aging US population: a trend toward decreasing rates and improved outcomes. JAMA Surg 2014;149:557-64.

[41] Ouakrim DA, Pizot C, Boniol M, Malvezzi M, Boniol M, Negri E, et al. Trends in colorectal cancer mortality in Europe: retrospective analysis of the WHO mortality database. Britisch Med J 2015;351:h4970.

[42] van Rooijen SJ, Huisman D, Stuijvenberg M, Stens J, Roumen RMH, Daams F, et al. Intraoperative modifiable risk factors of colorectal anastomotic leakage: why surgeons and anesthesiologists should act together. Int J Surg 2016;36: $183-200$.

[43] Miller TE, Roche AM, Mythen M. Fluid management and goal-directed therapy as an adjunct to Enhanced Recovery after Surgery (ERAS). Can J Anesth 2015;62:158-68.

[44] Dutch national Guidelines colorectal cancer. 2014. editor^, editors". City.

[45] Orsini RG, Rostoft S, Rutten HJ. Rectal cancer treatment in the elderly. In: Longo WEe a, editor. Modern management of cancer of the rectum. City: Springer-Verlag; 2015. p. 385-403. editor^, editors.

[46] Partridge JSL, Harari D, Dhesi JK. Frailty in the older surgical patient: a review. Age Ageing 2012;41:142-7.

[47] Fagard K, Leonard S, Deschodt M, Devriendt E, Wolthuis A, Prenen H, et al. The impact of frailty on postoperative outcomes in individuals aged 65 and over undergoing elective surgery for colorectal cancer: a systematic review. J Geriatr Oncol 2016;7:479-91.

[48] Lin HS, Watts JN, Peel NM, Hubbard RE. Frailty and post-operative outcomes in older surgical patients: a systematic review. BMC Geriatr 2016;16.

[49] Bruns ERJ, van den Heuvel B, Buskens CJ, van Duijvendijk P, Festen S, Wassenaar EB, et al. The effects of physical prehabilitation in elderly patients undergoing colorectal surgery: a systematic review. Colorectal Dis 2016;18: 267-77.

[50] Kristjansson SR, Nesbakken A, Jordhõy MS, Skovlund E, Audisio RA, Johannessen $\mathrm{HO}$, et al. Comprehensive geriatric assessment can predict complications in elderly patients after elective surgery for colorectal cancer: a prospective observational cohort study. Crit Rev Oncol-Hematol 2010;76: 208-17. 
[51] Huisman MG, van Leeuwen BL, Ugolini G, Montroni I, Spiliotis J, Stabilini C, et al. "Timed up \& go": a screening tool for predicting 30-day morbidity in onco-geriatric surgical patients? A multicenter cohort study. PLoS One 2014;9:e86863.

[52] Souwer ETD, Hultink D, Bastiaannet E, Hamaker ME, Schiphorst A, Pronk A, et al. The prognostic value of a geriatric risk score for older patients with colorectal cancer. Ann Surg Oncol 2019;26:71-8.

[53] Li C, Carli F, Lee L, Charlebois P, Stein B, Liberman AS, et al. Impact of trimodal prehabilitation program on functional recovery after colorectal cancer surgery: a pilot study. Surg Endosc 2013;27:1072-82.

[54] Barberan-Garcia A, Ubré M, Roca J, Lacy AM, Burgos F, Risco R, et al. Personalised prehabilitation in high-risk patients undergoing elective major abdominal surgery: a randomized blinded controlled trial. Ann Surg 2018;267:50-6.

[55] Mayo NE, Feldman L, Scott S, Zavorsky G, Kim DJ, Charlebois P, et al. Impact of preoperative change in physical function on postoperative recovery: argument supporting prehabilitation for colorectal surgery. Surgery 2011;150: 505-14.

[56] Minnella EM, Awasthi R, Gillies C, Fiore JF, Liberman AS, Charlebois P, et al. Patients with poor baseline walking capacity are most likely to improve their functional status with multimodal prehabilitation. Surgery 2016;160:1070-9.

[57] van Rooijen SJ, Molenaar CJL, Schep G, van Lieshout RHMA, Beijer S, Dubbers R, et al. Making patients fit for surgery: introducing a four pillar multimodal prehabilitation program in colorectal cancer. Am J Phys Med Rehabil 2019;98:888-96.

[58] Gillis C, Li C, Lee L, Awasthi R, Augustin B, Gamsa A, et al. Prehabilitation versus rehabilitation: a randomized control trial in patients undergoing colorectal resection for cancer. Anesthesiology 2014;121:937-47.

[59] Hijazi Y, Gondal U, Aziz O. A systematic review of prehabilitation programs in abdominal cancer surgery. Int J Surg 2017:39:156-62.

[60] West MA, Loughney L, Lythgoe D, Barben CP, Sripadam R, Kemp GJ, et al. Effect of prehabilitation on objectively measured physical fitness after neoadjuvant treatment in preoperative rectal cancer patients: a blinded interventional pilot study. Br J Anaesth 2015;114:244-51.

[61] Burden ST, Hill J, Shaffer JL, Todd C. Nutritional status of preoperative colorectal cancer patients. J Hum Nutr Diet 2010;23:402-7.

[62] Huisman MG, Veronese G, Audisio RA, Ugolini G, Montroni I, de Bock GH, et al. Poor nutritional status is associated with other geriatric domain impairments and adverse postoperative outcomes in onco-geriatric surgical patients - a multicentre cohort study. Eur J Surg Oncol 2016;42:1009-17.

[63] van Rooijen S, Carli F, Dalton S, Thomas G, Bojesen R, La Guen M, et al Multimodal prehabilitation in colorectal cancer patients to improve functional capacity and reduce postoperative complications: the first international randomized controlled trial for multimodal prehabilitation. BMC Canc 2019;19: 98.
[64] Gillis C, Loiselle S, Fiore JF, Awasthi R, Wykes L, Liberman AS, et al. Prehabilitation with whey protein supplementation on perioperative functional exercise capacity in patients undergoing colorectal resection for cancer: a pilot double-blinded randomized placebo-controlled trial. J Acad Nutr Diet 2016;116:802-12.

[65] Lemmens VEPP, Janssen-Heijnen MLG, Houterman S, Verheij KDGW, Martijn $\mathrm{H}$, van de Poll-Franse L, et al. Which comorbid conditions predict complications after surgery for colorectal cancer? World J Surg 2007;31: 192-9.

[66] Gooiker GA, Dekker JWT, Bastiaannet E, van der Geest LGM, Merkus JWS, van de Velde CJH, et al. Risk factors for excess mortality in the first year after curative surgery for colorectal cancer. Ann Surg Oncol 2012;19:2428-34.

[67] Biondi A, Vacante M, Ambrosino I, Cristaldi E, Pietrapertosa G, Basile F. Role of surgery for colorectal cancer in the elderly. World J Gastroenterol 2016;8: 606-13.

[68] Janssen-Heijnen MLG, Maas HAAM, Houterman S, Lemmens VEPP, Rutten HJT, Coebergh JWW. Comorbidity in older surgical cancer patients: influence on patient care and outcome. Eur J Canc 2007;43:2179-93.

[69] de Marco MF, Janssen-Heijnen MLG, van der Heijden LH, Coebergh JWW. Comorbidity and colorectal cancer according to subsite and stage: a population-based study. Eur J Canc 2000;36:95-9.

[70] Erichsen R, Huvath-Puhó E, Iversen LH, Lash TL, Sørensen HT. Does comorbidity interact with colorectal cancer to increase mortality? A nationwide population-based cohort study. Br J Canc 2013;109:2005-13.

[71] Manceau G, Mege D, Bridoux V, Lakkis Z, Venara A, Voron T, et al. Emergency surgery for obstructive colon cancer in elderly patients: results of a multicentric cohort of the French national surgical association. Dis Colon Rectum $2019 ; 62$.

[72] Amelung FJ, Borstlap WAA, Consten ECJ, Veld JV, van Halsema EE, Bemelman WA, et al. Propensity score-matched analysis of oncological outcome between stent as bridge to surgery and emergency resection in patients with malignant left-sided colonic obstruction. Br J Surg 2019;106.

[73] Arezzo A, Passera R, Lo Secco G, Verra M, Bonino MA, Targarona E, et al. Stent as bridge to surgery for left-sided malignant colonic obstruction reduces adverse events and stoma rate compared with emergency surgery: results of a systematic review and meta-analysis of randomized controlled trials. Gastrointest Endosc 2017;86:416-26.

[74] Fahim M, Dijksman LM, van Kessel CS, Smeeing D, Braaksma A, Derksen WJM, et al. Promising results of a new treatment in patients with bowel obstruction in colorectal surgery. Eur J Surg Oncol Aug 2019. https://doi.org/10.1016/ j.ejso.2019.10.011. In press.

[75] Hu WH, Cajas-Monson LC, Eisenstein S, Parry L, Cosman B, Ramamoorthy S Preoperative malnutrition assessments as predictors of postoperative mortality and morbidity in colorectal cancer: an analysis of ACS-NSQIP. Nutr J $2015 ; 14$. 